\title{
Daytime sleepiness in elderly Parkinson's disease patients and treatment with the psychostimulant modafinil: A preliminary study
}

This article was published in the following Dove Press journal:

Neuropsychiatric Disease and Treatment

25 March 2010

Number of times this article has been viewed

Johan Lökk

Institution of Neurobiology, Caring Sciences, and Society, Karolinska Institute, Stockholm, Sweden
Correspondence: Johan Lökk R94, Karolinska University Hospital Huddinge, SE- I 4186 Stockholm, Sweden Tel +46858580000

Fax +46858585482

Email johan.lokk@karolinska.se
Background: Patients with Parkinson's disease (PD) or Parkinsonian syndromes often report excessive daytime sleepiness (EDS). The aim of this study was to evaluate the effects of the psychostimulant modafinil on elderly, institutionalized, severely impaired PD patients with EDS.

Method: A three-week open study on ten institutionalized PD patients scoring $>10$ points on the Epworth Sleepiness Scale (ESS) with modafinil eventually on $100 \mathrm{mg}$ twice a day. Patients were assessed at the start, week 1, and week 3 with ESS, Clinical Global Impression (CGI) scale severity of PD and appetite.

Results: Reduction of ESS score and PD severity over time were found as well as a significant increase in appetite and reduction in CGI score.

Conclusion: Modafinil $100 \mathrm{mg}$ twice a day was safe and modestly effective for the treatment of EDS in elderly, institutionalized PD patients. Sustaining wakefulness throughout all stages of PD is crucial for participating in life, maintaining social life, and improving quality of life.

Keywords: Parkinson's disease, daytime sleepiness, Epworth sleepiness scale, psychostimulant

\section{Background}

Patients with Parkinsonian syndromes and Parkinson's disease (PD) often report excessive daytime sleepiness (EDS). ${ }^{1-4}$ This is a change in the state of consciousness with a difficulty to maintain wakefulness has no generally accepted definition. ${ }^{5}$ EDS can be identified using the Epworth Sleepiness Scale (ESS) with greater sensitivity and selectivity than other tests. ${ }^{5}$ EDS commonly occurs in PD patients with prevalence figures ranging from $15 \%$ (versus $1 \%-7 \%$ in controls) ${ }^{1}$ to $51 \% .^{2}$ There is an estimation of a $6 \%$ yearly increase of EDS in PD patients. ${ }^{3}$ EDS may cause reduced self esteem and self consciousness, impaired work performance and social interaction resulting in loss of independence and social isolation. ${ }^{6}$ Many patients do not have a clear awareness of their own sleepiness; even though EDS is often detrimental to a person's quality of life (QoL). These are also the consequences with the acquainted fatigue syndrome, which contrasts to EDS through the lack of physical and mental energy. The EDS state can also be misdiagnosed with depression and memory impairment. ${ }^{6}$ Various psychiatric and medical health problems may also arise with EDS and even fatal accidents have occurred when drivers have fallen asleep at the wheel. ${ }^{7}$ The development of such a pathological sleepiness seems to affect especially males, cognitively impaired patients with advanced disease, having orthostatic hypotension or drug-induced psychosis. ${ }^{8}$ After exclusion and treatment of any organic causes of EDS, the first step of treatment should be lifestyle interventions to improve the sleep pattern; this being a prerequisite 
for day-time alertness. This includes no caffeine, no intake of fluids after $6 \mathrm{pm}$, regular bedtime, normal room temperature, darkness and quietness in the bedroom. ${ }^{9}$ If EDS persists adjustment using dopaminergic and psychotropic drugs should be the next step, bearing in mind the balance between motor deterioration and alertness. A third is the possibility of administering a psychostimulant drug in a low and slow manner, to help the patient tune up his alertness, thereby possibly increasing their quality of life.

Psychostimulants have a long tradition in treating cancerrelated fatigue, depression associated with malignancies and opioid-induced sedation. One rather new psychostimulant, modafinil, was approved in 1998 for the use in attention deficit hyperactive disorder (ADHD) and has been used to treat fatigue in multiple sclerosis ${ }^{10}$ and amyotrophic lateral sclerosis. $^{11}$

Small studies with modafinil in PD patients have shown reduced EDS symptoms without worsening of Parkinsonian symptoms thereby allowing a further increase in dopaminergic therapy in patients previously unable to tolerate this because of EDS occurring as a side effect. ${ }^{12-14}$ In these studies modafinil was well tolerated at doses of 100-200 mg daily with few side-effects. ${ }^{13,14}$ However, other small studies with modafinil have failed to improve EDS on PD patients compared to placebo. ${ }^{15}$ Moreover, recently there is also data of a tentative neuroprotective effect of modafinil in a marmoset PD model. ${ }^{16}$

The action of modafinil is on the neuronal pathways in the sleep/awake-centers of the brain and is target selective in contrast to other central nervous system (CNS)-agents like amphetamine and methylphenidate. ${ }^{17}$ Modafinil is readily absorbed, reaching maximum plasma concentrations at 2-4 hours post-administration, and has a half-life of $12-15$ hours. The drug is primarily metabolized in the liver. A steady-state is achieved within 2-4 days, with subsequent excretion in the urine containing less than $10 \%$ as unchanged drug. Patients with compromised renal or hepatic function may have reduced elimination. Interaction studies suggest that modafinil stimulates some vital liver enzymes; which requires attention when patients have concomitant medication. ${ }^{18}$

To our knowledge there have been no studies performed with modafinil on elderly, institutionalized PD patients, with daytime sleepiness, prompting us study the effects of modafinil on this type of PD patient.

\section{Materials and methods}

This study was a 3-week, single-center, open study on elderly ( $\geq 70$ years), institutionalized PD patients recruited after being screened by the ESS by a nurse and scoring $>10$ points. The ESS is an 8-item questionnaire in which the probability to fall asleep is assessed for 8 different situations using a Likert scale ranging from 0 (never fall asleep) to 3 (high risk to fall asleep) with a maximum score of $24 .{ }^{19}$ The cut-off score of 10 points was chosen as it is two standard deviations (SDs) more than the mean results for 30 normal controls $(5.9 \pm 2.2)$. Included were patients all having idiopathic PD according to the United Kingdom Parkinson's Disease Society brain bank criteria ${ }^{20}$ and having a stable anti-PD medication dose 3 weeks prior to the study period. Excluded were those patients with other treatable causes for EDS such as: sleep apnea, rapid eye movement sleep behavior disorder (RBD), ${ }^{21}$ severe comorbidity or receiving hypnotics. Also excluded were patients with symptomatic or unstable cardiovascular disease, severe cognitive impairment (mini-mental test $[\mathrm{MMT}]<15$ ) or receiving antipsychotic and antidepressant medications.

The modafinil treatment started with $100 \mathrm{mg}$ in the morning for one week, followed by another $100 \mathrm{mg}$ at lunch for another 2 weeks.

At the start, after 1 week, and 3 weeks the following tests were performed: ESS ${ }^{19}$ severity of PD by Schwab \& England (S \& E), ${ }^{22}$ CGI-S (Clinical Global Impression - Severity scale), ${ }^{23}$ appetite score, body weight as well as side effects of treatment; all measurements were performed by two trained, independent nurses. Blood pressure and heart rate were also recorded; any increase of $>10 \%$ was regarded as adverse side effects as well as new onset patients' complaints. CGI-S contains a 7-point scale requiring the observer to rate the severity of the patient's illness at the time of assessment: $1=$ normal, $2=$ borderline ill, $3=$ mildly ill, $4=$ moderately ill, $5=$ markedly ill, $6=$ severely ill, or $7=$ extremely ill. The patients appetite was measured through a visual analogue scale (VAS) ranging from 0 (= no appetite, eats nothing on the plate) to 10 (= very good appetite, eats everything on the plate).

Patients, or their relatives gave their informed consent to participate before the start of the study. The study was approved by the regional ethical committee of Karolinska Institute, Stockholm.

\section{Statistics}

Descriptive statistical analysis was performed to determine the mean, standard deviation and percentage of the baseline demographic variables. A generalized linear model for repeated analysis was performed to assess treatment effects at each time point and to test whether treatment interacts with time. ESS, S \& E, CGI-S and appetite VAS were taken 
as dependent variables and gender was the between-subject factor. The level of statistical significance was specified at 0.05. Pairwise comparison using linear mixed model was made to determine if there were significant differences between different time points.

\section{Results}

Ten patients, five males and five females, were included in the study; age, gender, disease duration, height, weight and levodopa dose distributions are summarized in Table 1. The mean age was 79.7 years, the mean weight was $68.8 \mathrm{~kg}$, and the mean levodopa dose was $506 \mathrm{mg}$.

The mean scores and standard deviations of ESS, S \& E, CGI-S, and appetite VAS by time are displayed in Table 2 . There was a reduction of ESS score over time $(P<0.001)$ and a significant increase of $\mathrm{S} \& \mathrm{E}$ values over time $(P=0.011)$. A significant increase in appetite VAS score $(P=0.04)$ and a highly significant reduction in CGI-S score was observed $(P<0.001)$. No time group interaction in ESS score, $\mathrm{S} \& \mathrm{E}$, CGI-S and appetite VAS values, after initiation of treatment, was found. No significance between group differences was observed among men and women in ESS, S \& E, CGI-S, and appetite VAS. Pairwise comparison by using linear mixed model indicated that there was significant difference between time 0 and $1(P=0.001)$ and time 0 and $3(P<0.001)$.

No side effects of medication or change in weight were observed during the study period.

\section{Discussion}

Our data demonstrated that in this small, non-controlled study, $200 \mathrm{mg} /$ day of modafinil was safe and modestly effective for the treatment of EDS in institutionalized, elderly PD patients as measured by ESS. The global assessment was slightly improved as well appetite. The slight increase in alertness, in combination with a nonspecific pharmacodynamic effect of modafinil, might have had a positive effect

Table I Baseline characteristics of the study population

\begin{tabular}{ll}
\hline Characteristics & Mean (SD) \\
\hline Age (years) & $79.7(6.1)$ \\
Disease duration (years) & $15.2(4.1)$ \\
Levodopa dose $(\mathrm{mg})$ & $506.0(224.7)$ \\
Weight $(\mathrm{kg})$ & $68.8(10.9)$ \\
Height $(\mathrm{cm})$ & $169.6(10.7)$ \\
Male/females $(\mathrm{n}=10)$ & $5 / 5$ \\
\hline
\end{tabular}

Abbreviation: SD, standard deviation.
Table 2 Mean, standard deviation (SD), and results of the GLM repeated measure analysis of ESS, S \& E, CGI, and appetite (VASscore) over time

\begin{tabular}{|c|c|c|c|c|c|}
\hline \multirow[t]{2}{*}{ Characteristics } & \multicolumn{5}{|c|}{ Mean (SD) } \\
\hline & Baseline & I week & 3 weeks & F-statistic & $P$-value \\
\hline ESS & I $2.7(2.8)$ & II.3 (2.9) & $10.6(3.1)$ & 15.4 & $<0.001$ \\
\hline$S \& E$ & $42(13.2)$ & $46(13.5)$ & $47(14.2)$ & 6.0 & 0.01 \\
\hline CGI & $5.0(1.2)$ & $4.4(I . I)$ & $4.3(1.1)$ & 176.2 & $<0.00 \mathrm{I}$ \\
\hline Appetite VAS & $7.9(2.1)$ & $8.2(2.2)$ & $8.3(2.0)$ & 5.3 & 0.04 \\
\hline
\end{tabular}

Abbreviations: GLM, Generalized Linear Model; ESS, Epworth Sleepiness Scale; S \& E, Schwab \& England; CGI, Clinical Global Impression; SD, standard deviation;VAS, visual analogue scale.

on appetite and CGI-S. It might even be that the increased alertness had a general fortifying effect, as observed in the decreased disease severity measured by the $\mathrm{S} \& \mathrm{E}$; along with a possible effect of modafinil on the dopaminergic system, thereby increasing dopamine through the inhibition of dopamine transporter. ${ }^{24}$ Considering the long disease duration, the mean daily levodopa dose was rather low. However, the therapeutic window for pharmacological PD treatment tends to narrow over time due to adverse side effects; often prompting a dose reduction.

Given our study design, sample size and concomitant medications, it was not possible to determine whether the effect of modafinil was specific on any medication-induced sleepiness or the EDS related to the disease itself. However, this was a naturalistic study trying to mimic ordinary conditions in this type of patients. Another limit of this study is the lack of a control group, therefore the observed effect could be due to chance, the increased caregiver attention experienced by study participants or other external factors. However, the condition of these patients had been stable for several months and external conditions were kept as constant as possible, thereby minimizing the chance of any external influence affecting their condition. The use of ESS in elderly, institutionalized patients implies that some of the items of the questionnaire are not applicable to these patients, therefore the ESS scores must be interpreted with some caution. However, all patients were under the same conditions and in the analyses were ipsative, only comparing their own scores. The study design was set up with a rather short intervention duration due to safety reasons regarding these elderly, somewhat fragile patients and the possibility of any occurring side effects. However, there were no drug interactions or adverse side effects observed. A longer intervention study is warranted to determine if such positive 
effects, as seen in this pilot study are sustained. It is also important to include a greater number of elderly patients as they are often only sparsely participating or being excluded from pharmacological clinical trials. A better understanding of duration and dosage is crucial to balancing benefits and possible risks.

The dynamics of EDS is not fully understood, although there seems to be a complex interaction between PD disease, dysfunction in the sleep-wake regulatory system and pharmacological side effects of dopaminergic drugs. ${ }^{25}$ The prevalence of EDS increases with age ${ }^{26}$ and they are common in PD. ${ }^{27}$ Treatment possibilities of EDS in PD depend upon the condition itself, as well as the individual patient, and include a variety of nonpharmacological processes such as bright light therapy and short naps at regular intervals during the day ${ }^{28}$ as well as scheduled activities. ${ }^{29}$ Sometimes wakefulness-promoting medications are necessary. Such medications, independent of their mode of action, are prescribed to alleviate EDS. An off-label use of modafinil, as in this study, must have a well-founded rationale for use and must be undertaken, in agreement and understanding, with the patient and/or relatives, together with consideration of the cost-benefit issues. Such off-label use is a necessary function of the art of medicine and brings with it increased responsibilities for the prescriber. Liability will rest with the prescriber if the patient suffers adverse side effects. ${ }^{30}$ In addition, when prescribing off-label medications, the prescriber must make a careful risk assessment of the risks and benefits for the individual patients, as well as informing the patient that the prescription is off-label. It is noteworthy that prescribing a drug in an off-label manner is not prohibited for doctors and sometimes such a prescription can even constitute the standard care in many cases. For a long time levodopa has been prescribed for restless legs syndrome and during the last years cholinesterase inhibitors are prescribed off-label to a remarkable proportion of patients with vascular dementia, Parkinson's disease dementia and Lewy Body dementia. ${ }^{31}$

Daytime sleepiness may cause social handicap and impair QoL and has long been neglected among PD issues. Sustaining wakefulness throughout all stages of the disease is crucial for participating in life and maintaining a social life. Thus, every measure taken to improve wakefulness in PD patients is of the utmost importance, especially in elderly patients as they often suffer from comorbidity and polypharmacy, both potential contributors to sleepiness. Therefore, in this study, we exclusively recruited elderly PD patients. Professional caregivers as well as relatives need to be observant in assessing daytime sleepiness in PD patients as it can impair QoL for patients and probably their caregivers as well.

\section{Disclosure}

The authors report no conflicts of interest.

\section{References}

1. Larsen JP. Sleep disorders in Parkinson's disease. Adv Neurol. 2003;91:329-334.

2. Hobson DE, Lang AE, Martin WR, Razmy A, Rivest J, Fleming J. Excessive daytime sleepiness and sudden-onset sleep in Parkinson disease: a survey by the Canadian Movement Disorders Group. JAMA. 2002;287:455-463.

3. Gjerstad MD, Aarsland D, Larsen JP. Development of daytime somnolence over time in Parkinson's disease. Neurology. 2002;58:1544-1546.

4. Arnulf I. Excessive daytime sleepiness in parkinsonism. Sleep Med Rev. 2005;9:185-200.

5. George PT. Sleepiness, troika of consciousness cycle, and the Epworth sleepiness scale. Sleep Breath. 2001;5:181-191.

6. Black J, Duntley SP, Bogan RK, O'Malley MB. Recent advantages in the management of excessive daytime sleepiness. CNS Spectr. 2007;12:1-14.

7. Meindorfner C, Körner Y, Möller JC, Stiasny-Kolster K, Oertel WH, Krüger HP. Driving in Parkinson's disease: mobility, accidents, and sudden onset of sleep at the wheel. Mov Disord. 2005;20:832-842.

8. Rye DB. Excessive daytime sleepiness and unintended sleep in Parkinson's disease. Curr Neurol Neurosci Rep. 2006;6:169-176.

9. Cole C, Richards K. Sleep disruption in older adults. Harmful and by no means inevitable, it should be assessed for and treated. Am J Nurs. 2007;107:40-49.

10. Nagels G, D'hooghe MB, Vleugels L, Kos D, Despontin M, De Deyn PP. P300 and treatment effect of modafinil on fatigue in multiple sclerosis. J Clin Neurosci. 2007;14:33-40.

11. Prommer E. Modafinil: is it ready for prime time? J Opioid Manag. 2006;2:130-136.

12. Nieves AV, Lang AE. Treatment of excessive daytime sleepiness in patients with Parkinson's disease with modafinil. Clin Neuropharmacol. 2002;25:111-114.

13. Högl B, Saletu M, Brandauer E, et al. Modafinil for the treatment of daytime sleepiness in Parkinson's disease: a double-blind, randomized, cross-over, placebo-controlled polygraphic trial. Sleep. 2002;25: 905-909.

14. Adler CH, Caviness JN, Hentz JG, Lind M, Tiede J. Randomized trial of modafinil for treating subjective daytime sleepiness in patients with Parkinson's disease. Mov Disord. 2003;18:287-293.

15. Ondo WG, Fayle R, Atassi F, Jankovic J. Modafinil for daytime somnolence in Parkinson's disease: double blind, placebo controlled parallel trial. J Neurol Neurosurg Psychiatry. 2005;76:1636-1639.

16. van Vliet SA, Blezer EL, Jongsman MJ, Vanwersch RA, Olivier B, Philippens IH. Exploring the neuroprotective effects of modafinil in a marmoset Parkinson model with immunohistochemistry, magnetic resonance imaging and spectroscopy. Brain Res. 2008;11189:219-228.

17. Robertson P Jr, Hellriegel ET. Clinical pharmacokinetic profile of modafinil. Clin Pharmacokinet. 2003;42:123-137.

18. FASS Pharmaceutical Specialities in Sweden. Available from: http:// www.fass.se. Accessed February 10, 2010.

19. Johns MW. A new method for measuring daytime sleepiness: the Epworth Sleepiness Scale. Sleep. 1991;14:540-545.

20. Hughes AJ, Daniel SE, Kilford L, Lees AJ. Accuracy of clinical diagnosis of idiopathic Parkinon's disease: a clinico-pathological study of 100 cases. J Neurol Neurosurg Psychiatry. 1992;55:181-184.

21. Postuma RB, Gagnon JF, Vendette M, Charland K, Montplaisir J. REM sleep behaviour disorder in Parkinson's disease is associated with specific motor features. J Neurol Neurosurg Psychiatry. 2008;79:1117-1121. 
22. Schwab RS, England AC. Projection technique for evaluating surgery in Parkinson's disease. In: Gillingham FJ, Donaldson IML, editors. Third Symposium on Parkinson's Disease E \& S. Edinburgh, UK: Livingstone; 1969.

23. Schneider LS, Olin JT. Clinical Global Impression of Change. Clinical global impressions in Alzheimers clinical trials. Int Psychogeriatr. 1996;8:277-290

24. Mignot E, Nishino S, Guilleminault C, Dement WS. Modafinil binds to the dopamine uptake carrier site with low affinity. Sleep. 1994;17 436-437.

25. Happe S, Baier BC, Helmschmied K, Meller J, Tatsch K, Paulus W. Association of daytime sleepiness with nigrostriatal dopaminergic degeneration in early Parkinson's disease. J Neurol. 2007;254 1037-1043.

26. Kayukawa Y, Kogawa S, Tadano F, et al. Sleep problems in the aged in relation to senility. Psychiatry Clin Neurosci. 1998;52:190-192.
27. Jahan I, Hauser RA, Sullivan KL, Miller A, Zesiewisc TA. Sleep disorders in Parkinson's disease. Neuropsychiatr Dis Treat. 2009;5: 535-540.

28. Tamaki M, Shirota A, Tanaka H, Hayashi M, Hori T. Effects of a daytime nap in the aged. Psychiatry Clin Neurosci. 1999;53: 273-275.

29. Choo KL, Guilleminault C. Narcolepsy and idiopathic hypersomnolence. Clin Chest Med. 1998;19:169-181.

30. Haw C, Stubbs J. Off-label use of anti-psychotics: are we mad? Expert Opin Drug Saf. 2007;6:533-545.

31. Frisoni GB, Canu E, Geroldi C, Brignoli B, Anglani L, Galuzzi S, et al. Prescription patterns and efficacy of drugs for patients with dementia: physicians' perspective in Italy. Aging Clin Exp Res. 2007; 19:349-355.

\section{Publish your work in this journal}

Neuropsychiatric Disease and Treatment is an international, peerreviewed journal of clinical therapeutics and pharmacology focusing on concise rapid reporting of clinical or pre-clinical studies on a range of neuropsychiatric and neurological disorders. This journal is indexed on PubMed Central, the 'PsycINFO' database and CAS, and is the official

Submit your manuscript here: http://www.dovepress.com/neuropsychiatric-disease-and-treatment-journal journal of The International Neuropsychiatric Association (INA). The manuscript management system is completely online and includes a very quick and fair peer-review system, which is all easy to use. Visit http://www.dovepress.com/testimonials.php to read real quotes from published authors. 